\title{
Um caso de tumor do cerebello
}

Trabalho lido na Sociedade Arnaldo Vieira de Carvalho, pelo Academico Edgard Pinto Cezar, da Faculdade de Medicina de S. Paulo.

Meus senhores:

O caso que temos a honra de apresentar perante esta Sociedade, é daquelles que proporc:onam grande copia de ensinamentos aos que têm a felicidade de acompanhal-o durante toda a sua evolução. Ensinamentos de ordem moral, pois nos deixam impregnados da confiança que devemos ter nos dados da semeiologia, o que nos traz a grande satisfacção intima da certeza do diagnostico; ensimamentos scientificos, pois o actual caso vale por uma experiencia "in anima nobili" de physiologia, experiencia essa feita pela propria natureza em uma das man.festações de seus multiplos caprichos.

Passemos a estudar o nosso caso.

Em 19 de Junho do anno p. p. dava entrada na Santa Casa, na 3.a M. H., serviço do Prof. Ovidio Pires de Campos, o Sr. S. N., brasileiro, com 33 annos de idade, casado, procedente de Sorocaba, neste Estado, onde, exercia a profissão de barbeiro. Para seguirmos a marcha natural de um caso clinico, vejamos quaes os dados que nos forneceu deante do nosso interragatorio. Nada de importante quanto aos seus antecedentes hereditarios. Quanto aos antecedentes pessoaes, disse-nos que sempre foi forte, negando mesmo ter as molestias peculiares á infancia. Entretanto teve aos 4 annos febre typhoide com recahida, restabelecendo-se apesar disso, rapidamente. Assás accidentado é o seu passado venereo: aos 14 annos contraiu uma gonorrhéa e 2 ou 3 mezes após lhe appareceram varios cancros molles distribu:dos por quasi todo o penis. Não ligou a devida importancia á. essas molestias, só fazendo um ligeiro tratamento local das ulcerações. Dois annos mais tarde casou-se, e, de então para cá teve sua mulher dois nat:mortos. Mesmo depois de casado, ha cerca de seis annos atráz, teve novamente cancros molles a ainda desta vez, não se submetteu ao menor tratamento. 
Em Junho de 1924 teve um outro cancro, esse porém, duro, syp:ilico, segunáno o diagnostico de um facultativo que consultou na occasião. Como tratamento fez apenas uma injecção de Bismoxyl.

Até a sua entrada para o Hospital era grande tabag sta: uasva imoderadamente das bebidas alcoolicas, só deixando este vicio, pelo apparecimento dos symptomas da sua actual molestia. Vejamos agora como se iniciou o seu mal.

A primeira manifestação surgiu em Dezembro de 1924: foi sentindo uma fraqueza nas pernas (sic). e repetidamente ancias de vomito. Dois ou trez dias depois foi acomettido de um estado vertiginoso acompanhado de febre alta, o que o obrigou a guardar o leito. Já então sentia o doente fortissima cephaléa, localisada principalmente nas regiões temporal e frontal, Julgando-se atacado por uma indigestão, chamou um medico que fez o diagnostico de syphilis, applicando-lhe o tratamento arsenical pelo Neo-Salvarsan, tendo tomado 5 injecções desse preparado. Isso produziu em seu estado grande melhora, podendo levantar-se e trabalhar em sua profissão durante 2 dias, dedicand'o-se por mais tempo em seu "salão" a fazer serviços leves, até que na segunda quinzena de Janeiro p. p. peorou consideravelmente. A cephaléa se tornou intensa e insupportavel: sobrevieram vomitos matinaes e diarios que surg.am facilmente sem serem precedidos de nauseas.

Pouco depois lhe apparecia. uma paresia de ambas as pernas com intervallo de 6 dias entre uma e outra, não se recordando qual a attingida em primeiro logar. Continuava a ter vertigens diariamente e só com dificuldades conseguia se locomover devido a grande debilidade das perruas. Em Maio ultimo começou a sentir perturbações para o lado da vista que se mostrava embaraçada e em seguida notou que estava enxergando os objectos duplamente (diplopia). Notando que meihora alguma obtinha em sua cidade (Sorocaba), resolveu vir para esta Capital para se internar na Santa Casa, o que fez, como já o dissemos, em Junho do anno p. p.

Tratava-se de um individuo de estatura mediana, de bôa constituição esqueletica, apresentando musculatura geral pouco desenvolvida. Para os lados dos apparelhos respiratorio, circulatorio e digestivo, nada nos revelava pelo exame geral. O mesmo podiemos dizer do apparelho urinario. Deante dos seus antecedentes venereos tão acidentados, tratamos logo de pesquizar os signaes de syphilis. 
Constatamos o infarctamento ligeiro do gangl:o epitrochleano direito, assim camo de todia a pleiade dos inguinaes. As dores osteocapas eram pouco accentuadas. Pupillas normaes pela inspecção. $O$ nosso exame tornouse productivo quando investigamos as alterações para o lado do systema nervoso.

Verificamos uma accentuada atonia dos membros inferiores facto este narrado pelo prcprio doente, sob a rubrica de "grande fraqueza nas pernas". A' sua farça muscular estava muito diminuida nesse segmento do corpo; embora não fosse por nos medida, éra facilmente verificavel. Pelo exame dos reflexos notamos a exaltação do patellar e achilian = je ambos os lados. Não eram presentes o signal de Babinscki e o clono, tanto da rotula como do pé. Nos membros superiores os reflexos eram mais ou menos normaes. Os cutaneos (abdominaes, cremasteirnos e gluteos), todos conservados. Ausencia de Argyll-Robertson, mas as pupillas reagiam preguiçosamente á luz. Deante de taes signaes tratamos de verificar as alterações que poderia aprezentar parao lado da motilidade. Ordenando ao doente que andasse ao longo da enfermaria, pudemos constatar um facto importantissimo: tinha elle dado alguns passos, com os braços abertos, como que se equilibrando, e eis que em dado momento apresenta uma latero-pulsão das mais typicas. Esse facto pudemos notar repetidlas vezes e, observação importante, a latero-pulsão éra sempre para o lado direito. Interrogando-o si anteriormente apresentava esse phenomeno respondeu affirmativamente e ainda mais, disse que muita gente, em sua cidade natal, julgava-o embriagado quando o via andar. Deante desse quadro nos surgiu logo em mente a hypothese de se tratar de um syndromo cerebellar.

Foi então que dirigimos nossas attenções para esse lado, fazendo a pesquiza dos outros s.gnaes que individualizam esse syndromo. Com grande facilidade pudemos notar para os lados dos globos oculares a presença do nystagmus; mas ,este phenomeno, não era constante; como mais tarde pudemos constatar. A dysmetria éra muito ligeira e só constatavel para lado direito. Mais accentuada éra a adiadoćocynesia, que, como o pherromeno anterior, só éra presente para o lado direito. Diante de taes manifestações, mister se tornava uma puncção lombar. 'Esta foi immediatamente feita e confirmando o que surpeitavamos, vimos que nem bem a agulha penetrava no espaço sub-arachnoidiano, o liquido "jorrava" com uma pressão extraordiniaria, a uma distancia de 10 a 15 cms. Era um liquida claro, crystallino, de aspecto perfeitamente normal. A areacção de Wassermann foi ahi in- 
teiramente negativa e o exame cytologico revelou 3 lymphocytos por mm. q. Outro exame de absoluta necessidade éra o de fundo do olho. Este foi feito pelo Dr. Pereira Comes em 21-6. 925 e'o resultado veio corroborar os factos anteriores e ao mesmo tempo nos trouxe dados importantissimos para o nosso diagnostico. Eis o laudo do seu exame:

A. O. Fundi - franca hyper-hemia venosa especialmente do O. D. Visão - O. D. 1/3. O. E. 2/3.

Em 4-7-925 foi este exame repetido pelo mesmo especialista com o seguinte resultado: Visão: mesmas condições. Reacções pupillares mais preguiçosas. Papilledema de A. O. especialmente do O. D. Recapitulemos um pouco em synthese os symptmas do nosso doente: vomitos, vertigens, cephaléa, perturbações da visão, papilledemas, puncção lombar com liquido saindo em jorros... Isso tudo é a mesma cousa que uma equação cujo resultado é hypertensão craneana. De fácto, em nosso doente o syndromo de hypertensão craneana se patenteava de uma maneira indubitavel. Como causa dessa hypertensão só éra cabivel em nosso doente, admittir-se um tumor, intra-craneano, pois todas às outras hypotheses não resistiam á uma analyse bem feita. Mas, o affirmar-se cada uma mais importante que outra, restava a resolver. Em primeiro logar, necessitavamos saber de que natureza éra o tumor, em segundo, qual a sua local sação. De que especie de tumor se trataria? Um tuberculo? Uma gomma? Uma neo-formação benigna? Uma neo-formação maligna? Quanto á primeira hypothese, tuberculose não podiamos admittir. Sendo geralmente secundaria, e não tendo sido constatada lesão primaria, e mais, que tudo o exame do liquido não nos permittia um diagnostico dessa natureza. Quanto á segunda hypothese, a de tuma gomma, eis aqui o que mais nos pareceu provavel apesar do exame cytologico e do Wassermann negativo no liquido. Realmente o passado verereo do nosso doente éra dos mais accidentados. Repetidamente contagiado pelo bacillo de Ducrey e no ultimo contagio uma ulcera com diagnostico medico de cancro duro. Ainda mais, a existencia de ganglios infarctados, de dôres osteoscopas, de dois nati-mortos entre seus filhos, e, para nos convencer a melhora accentuada com o uso do Neo-Salvarsan, tudo mos levava a crer na existencia de um tumor especifico. Não podiamos afastar essa hypothese, mesmo na presença de um Wassermann negativo no liquido cephalo-rachidiano. Essa admiravel prov'a clinica, como bem o sabemos não é de molóes a mos permittir uma tal attitude. $O$ exame cytologico tambem não éra sufficiente para derribar a nossa hypothese; ; esta ficava por- 
tanto de pé Quanto ás outras causas, os outros tumores, se me a figurava que dado algum possuiamos para aff:rmar a sua existencia. $\mathrm{Na}$ realidade, emquanto tantas provas nos auctorisavam a crer numa syphilis, bem pouco ou quasi nada nos levava a acreditar na existencia de um tumor de outra especie. Mas... acompanhando o nosso caso, instituindo de accordo com as conviçóes o tratamento anti-luetico intensivo, somente notamos que ao envez de melhorar a molestia se aggravava, o doente emmagrecia consideravelmente e mais ainda se accentuava o seu estado de torpor. Não quizemos crer, rembora já desconfiados que fracassasse completamente a hypothese de syphilis. Por mais algum tempo foi experimentado a terapeutica especifica, mas... o proprio tempo se encarregou de nos mostrar o engano em que laboravamos!

Deante da absoluta falta de qualquer melhora com tratamento instituido, deante da debacle que apersentava o doente já então entrado em accentuada cachexia, não pudemos mais ros sustentar na hypothese de se tratar de um mal syphilitico. Éra forçoso que mudassemos o modo de pensar. E assim aconteceu.

Só restava admittir-se a eixstencia de uma neoplasia benigma, ou talvez maligna.

A primeira dessas hypotheses nos éra mais sustentavel deante da sua grande preponderancia nas estatisticas (70\% segundo $\mathrm{H}$. Claud). Si havia um tumor dessa natureza, o unico recurso therapeutico seria uma intervenção cirurgica. Mas para que esta fosse executada, éra necessario que resolvessemos a segunda parte da questão, isto é, fizessemos o diagnostico da localisação. Em que parte do encephalo se localisaria o tumor? E o que tentamos resolver e o resultado final nos veio revelar de maneira a mais cabal a verdade dos factos pre-estabelecidos.

A hypothese de um tumor cerebral não nos foi difficil afastar. Dos lobos do cerebro o unico que poderia entrar em nossas cogitações seria o frontal, que dá ás vezes uma symptomatologia semelhante á cerebellar. Mas me parece que está hoje mais ou menos assente que as perturbações psychicas estão entre as mais caracteristicas da slesões deste lobo. $\mathrm{O}$ nosso doente no entanto, não apresentava perturbaçōes dessa ordem, conservando mesmo nos periodos em que mais se acceutuavam os outros phenomens, uma lucidez de espir.to bastante apreciavel. Não apresentava tambem o phenomeno da "moria" que alguns autores dizem ser mais frequentes nas lesões desta parte do cerebro. Mas de todos os symptomas o que com mais segurança nos fez 
afastar a hypothese de um tumor do lobo frontal foi a ausencia do signal de Kenedy, isto é, a falta da atrophia papillar do lado lesado e palpillite de estase do lado opposto á lesão. Está é um signal de grande valia pathognomon co mesmo dás lesóes tumoraes do lobo frontal e que tem sido muito. bem estudado em São Paulo pelo Dr. Nova Gomes. Como vemos, a hypothese de um tumor do lobo frontal não póde ser sustentada. Si não está no lobo frontal, muito menos se pode admuitir que esteja em qualquer dos outros, cujas symptomatologias são muito ruidosas. Uma localisação bulbạar ou protuberencial não podia tambem" ser admittida. Nestes casos os pheno-, menos em relação com a motric dade e sensibilidiade são muito mais accentuados e sempre são affectados varios pares craneanos. Mas ,como já citamos, apresentava o nosso doente signaes cerebellares que podiam ser distinctos no meio dos que corriam por conta da hypertensão craneana. Assim, como já o dissemos, apresentava elle titubeação na marcha, marcha ebria, latero-pulsão, dysmetria, ad adococynesia, hypotonia, nystagums, etc.

Diante de um tal quadro, não estava patente um syndromo cerebellar? Mas mesmo isso pensando ou mesmo admittindo, como era natural, ainda permaneciam grandes incertezas. Tratar-se-ia de um tumor do cerebello propriamente ou de um caso em que esse orgão se achasse affectado por simples visinhança? Eis uma difficuldade não muito pequena. Não poderia ser um caso de tumor do angulo-cerebellar?

Analysemos esta hypothese. Todos os signaes que o doente apresentava nessa occasião seriam compativeis com um tumor localisado neste ponto, como então adimittil-o? Sabemos que os "tumores do angulo ponto cerebelllar são de começo insidioso, exteriorssando quasi sempre em primeiro logar pelos signaes de localisação, isto é, signaes consequentes á com. pressão da região, os quaes, ás vezes, podem ser os uniços a existir" (These do Prof. Flaminio Favero).

Orà, esses signaes de 'sua lócalisação são dados pelo compromettimento do oitávo par craneano principalmente, o que é constante, e tambem do setímo, sexto e qu nto do mesmo lado de accordo com a ordem de frequencia desses compromettimentos. Não foi isso que observamos no nosso caso. Deipois de decorridos sete mezies do inicio da molest:a, as perturbações dos nervos craneanos são bem discretas. $S i$ se tratasse de um tumor do "angullo" ser.a quasi certo que o auditivo do lado affectado já estaria inteiramente destruido. Em nosso caso não era isso que se dava. Eis o resultado de exame do ouvido procedido pelo Dr. Francisco Hartung, em 27-6-925: 


\begin{tabular}{lll}
\multicolumn{3}{c}{ EXAME DE AUDIÇÃO } \\
Ouvido D. & Provas & \\
normal & $\mathrm{M} . \mathrm{V}$. & Ouvido E. \\
positivo & $\mathrm{Ci} 4$ & normal \\
normal & $\mathrm{Sch}$ & positivo \\
positivo & $\mathrm{R}$. & normal \\
positivo & $\mathrm{W}$. & normal \\
ystagmus experimental & & \\
$0^{\circ}-0^{\prime \prime}$ prova calorica 1'- 10" & \\
10", &, rotatoria 50"
\end{tabular}

Hyper-irritabilidade do labyrinto esquerdo.

Hypo-irritabilidade do labyrinto direito.

Ao lado disso a falta de compromettimento de outros nervos craneanos já nos fornece dados sufficientes para affastarmos a hypothese de um tumor do angulo ponto-cerebellar.

Sómente se poude notar nos ultimos dias de molestia uma ligeira paresia intermittente, do VI par do lado direito. Só esse facto não nos podia levar a affirmar um tumor do angulo. Já que não se podia tratar de um tumor do angulo ponto-cerebellar, a unica hypothese restante seria a de um tumor do cerebello propriamente. Com esta hypothese podia se compreender a grande hypertensão com a accentuadissima papillite de estase sem que houvesse perturbações para o lado dos nervos craneanos e ao mesmo tempo o syndromo cerebellar achava a sua mais cabal explicação.

Um syndromo de hyper-tensão craneano como o apresentado pelo nosso doente ecom a symptomatologia restante que apresentou, só éra cabivel com um tumor do cerebello propriamerite dito. Uma vez isso assente não nos fó difficil dizer em que parte do orgão devia se assestar a lesão. Como já o dissemos toda a symptomatologia cerebellar do nosso doente éra para o lado direito. Assim tinhamos a latero-pulsão, a adiadococynesia para só citarmos os symptomas quie com mais evidencia se apresentavam, só éram verificaveis para o lado direito. Si juntarmos a isso o resultado dos exames de fundo de olho, de ouvido e a paresia dó recto externo (VI par); que mais tarde se apresentou, chegaremos á conclusão irrefutavel de que o tumor só podia estar alojado no lobo direito do ceerbello. Uma vez isso bem assente, estava resolvida a ultima difficuldade, o ultimo problema da alçada do clinico. Mister se fazia então que fosse executadia a intervenção 
cirurgica, o ultimo recurso medico e a ultima esperança para o, nosso doente. Coube ao Prof. Antonio Candido de Camargo essa dificil e arriscada empreza. No dia aprasado o doente é levado a sala aseptica e uma vez feita a rachi-anesthesia, com o trepano é aberta a loja cerebral posterior de maneira a se poder explorar ambos os lobos lateraes .0 habil cirurgião, uma vez aberta a tenda do cerebello, explora cuidadosamente tod'a a região em todos os sentidos possiveis sem nada poder encontrar... Depois de demorado exame, resolveu fechar a aberturá feita, pois se convenceu de que nada havia desse lado do cerebello. Quer os vermis, quer as massas lateraes da região, se achavam com o aspecto normal e á palpação crảneana e grande erro. Mlas si o tumor não estava no cerebello e nem no angulo, em encerrava-se a cperação attestando um formidavel fracasso de diagnostico. Estavamos verdadeiramente perplexos e não sabiamos a que attribuir tão que ponto do encephalo poideria estar já que éra fora de duvida que havia um tumor? Não sabiamos dizer.

Mas, meus Srs., quanta vez é a infelicidade alheia que nos vem trazer os nossos melhores rensinamentos?... Pois ainda desta vez foi o que succedeu. $\mathrm{O}$ infeliz moço, não pcdendo resistir á grave intervenção cirrurgica, veio a fallecer na tarde desse mesmo dia. Foi com a sua morte que tudo se esclareceu pela autopsia de seu cadaver, praticada pelo Dr. João Montenegro, auxiliado pelo Dr. Parsi. Mesmo depois de retirada toda a massa encephalica não se sabia dizer se havia ou não tumor encephalico. Tudo parecia normal, a não ser o traumatismo de ambos os lobos cerebellaxres soffridos durante a operação. Um exame mais attento mostrava um augmento, ligeiro no volume do lobo direito do cerebello. Talhado o orgão em sentido horizontal, tudo se esclarececeu. Existia de facto um tumor no interior do lobo direito do cerebelilo, tumor que se confundia com o tecido normal do orgão pela sua côr e consistencia. Era impossivel ao cirurgião verificar a sua existencia, e mesmo que se verificasse, seria inextirpavel. Confirmava-se, assim "in totum" o diagnost.co clinico e ao mesmo tempo salvava-se á reputação do cirurgião: $O$ exame histologico püocedido pelo Dr.' João Montenegro mostrou tratar-se de um glioma, o que pudemos verificar pessoalmente no $H$. de Juquery applicando a coloração especifica da glia pelo processo de Lhermitte. 